\title{
A Study of the Leading Factors that Induced Confidence in the Foreign Investors for Investing in Real Estate Business for the Period 1970- 2019
}

Diaa Khalaf Ahmed AlQatawneh*, Prof Ahmed Azrin Adnan, Sameer A. A. AlZoughool, Tamer Hussain Ahmed Alqudah

\footnotetext{
${ }^{1,3,4}$ Phd Students, UniSZA University, Kuala Terengganu, Malaysia
}

${ }^{2}$ Lectrure, UniSZA University, Kuala Terengganu, Malaysia

DOI: $10.36347 /$ sjebm.2020.v07i01.007

| Received: 16.12.2019 | Accepted: 24.12.2019 | Published: 29.01.2020

*Corresponding author: Diaa Khalaf Ahmed AlQatawneh

Abstract

Original Research Article

The purpose of the present paper is to outline the trend of the UAE in the real estate market from 1970 till 2019 and reflect the attitude of the foreign investors and help the readers understand the factors that have attracted them to make investment in the property sector in the UAE. The research is descriptive in nature and collects the data based on the empirical previous studies and the statistical data retrieved from the World Bank and UN development websites. The overall research study focuses on the general trend followed between the years $1970-2010$ and analyze the situation from 2010-2019 to showcase the changes in the UAE property sector. The findings of the study reveal that however, the UAE has shown consistent positive trend from 1970-2010, however, in 2016 till 2019, the country has shown decline in its property sector due to several nation's strict policies. But since the initiation of the Dubai Expo 2020 and Dubai Global City, the foreigners have shown significant interest in making investment in the region's property sector. Keywords: Leading Factors, Foreign Investors, Real Estate Business.

Copyright @ 2020: This is an open-access article distributed under the terms of the Creative Commons Attribution license which permits unrestricted use, distribution, and reproduction in any medium for non-commercial use (NonCommercial, or CC-BY-NC) provided the original author and source are credited.

\section{INTRODUCTION}

According to the recent survey report [1], it is revealed that the United Arab Emirates (UAE) has seen a territorial boom in the past few years due to the plethora of fundamental economic strengths of the region around the globe. Particularly, Dubai Expo 2020 is anticipated to open the landscape of UAE for the international investors, as mentioned by Hodgson [2] in his article. Another reason for this progression is linked with the implementation of governmental policies that has reduced its economic independence on the oil industry and started endorsing policies in non-oil sector as well. Out of non-oil industries, two important areas have gotten increased importance; real estate sector and tourism sector. According to Chinn \& Ito [3] these two areas are proved as two essential areas where the countries can progress and enhance their economic development. In the past few years, UAE real market has seen considerable improvement, which is showcased from the recent development in the Dubai and Abu Dhabi property markets and the initiation of Dubai Expo 2020. Moreover, Dubai's Cityscape Global 2019 has also played a major role in opening the UAE's global real estate investment [2].
The United Arab Emirates (UAE) is a league of seven governments: Abu Dhabi, Ajman, Dubai, Fujairah, Ras Al-Khaimah, Sharjah, and Umm alQaiwain. According to Crompton [4] it is concluded that UAE is the world's ninth largest region enriched with natural resources, however, the increased globalization has enforced the region to formulate the strategies that attempts to diversify its economic reliance not only on the oil sector but to integrate the real estate market with the international market can bring prosperity to the economic development of the UAE. This is linked to the increasing trend towards globalization in the last two decades that has initiated the continuous international inflow to the emerging economies and increased growth opportunities in the host countries such as transfer of technology, skills creation and upgraded managerial skills [5]. In the context of the UAE real estate sector, the research reflects that the foreign investors have now increased propensity to make their investments and contribute in the economic progression of the region. This is also evidenced from the past research studies that various scholars [6] have theoretically and empirically showed the significance of real estate market in the economic 
prosperity of the country, yet, in the context of UAE, the literature lacks the reflection of those leading factors that has increased the confidence level in the foreign investors in the property market of the UAE.

Aljifri \& Ahmad [7] stated that the UAE's government demonstrates favorable business atmosphere, which is showcased from the cultural diversity with high standard of living that has enforced the region to climb the ladder of success, despite the financial crisis in 2007 damaged the entire world but it did not affect the emerging economy of the UAE. In the report released in 2013, UAE provided approximately $60 \%$ of the property boom in the GCC (Gulf Council Countries), with solely Dubai furnishing $48 \%$ of the total GCC nations. During 2003-2007, the real estate and construction industry in the UAE progressed as the emerging nation for the global investors and marked the country as one of the leading nations that has freehold status for the property. Nevertheless, as illustrated by Modarress, Ansari \& Lockwood [8] property sector is an alluring market for both the national residents and foreign investor in the UAE. For instance, Emaar, Nakheel, Aldar and Damac are some of the notable developers that had the major investments in the UAE real estate market during 2007 till 2014.

Furthermore, El-Mahmah [9] illustrated that the UAE real estate market is volatile, which is reflected from the country's 2014 statistical value presented by the Census.gov house prices in Dubai. According to the author of the study, the statistical results reflected that the apartment prices in the UAE increased up to $10 \%$ in the international real estate market in 2014, however, in the later years, the rent prices went down in the foreign market. To understand all these fluctuations in the real estate market in the UAE region and the present booming trend that has attracted enormous foreign investors to invest in the real estate sector, the present article is designed to discuss the history of the real estate market in the UAE region. In this way, the readers can understand the ups and downs of the real estate market in the UAE and find those factors that have now enforced the global investors to invest in the real estate market in the UAE.

\section{RESEARCH OBJECTIVES}

\section{The basic Objectives of the present article is;}

- To highlight and summarize the regional fluctuations in the UAE real estate market from the period 1970-2019

- To discuss the factors that have induced the confidence in the foreign investors to invest in the real estate market in the UAE from the period 1970-2018

\section{RESEARCH METHODOLOGY}

In the present article, the empirical approach has been adopted, which considers the previous studies and research as the source of data collection [10]. The research approach is carried out in the theoretical context, which obtains the information from academic articles, analytical reviews, online authentic resources ( World Bank IMF, UNDP) and previous academic journals in the related topic. In the present article, the historical market changes and anticipated market forecasts with respect to the UAE market has been investigated and measured along with the foreign investors' attitude towards the UAE real estate market. The data collected from the secondary sources offered the detailed overview of the UAE market and volatility of the UAE market for the period of 49 years.

\section{DISCUSSION}

\section{History of Real Estate Market in the UAE from 1970-2010}

The analysis of the previous research studies show that UAE has shown considerable improvement in its overall economic progression in various non-oil sectors for the past 50 years [7]. There is a summarized overview of the nation's development for the period 1970-2010 to help the readers understand how the region has emerged for the past two decades.

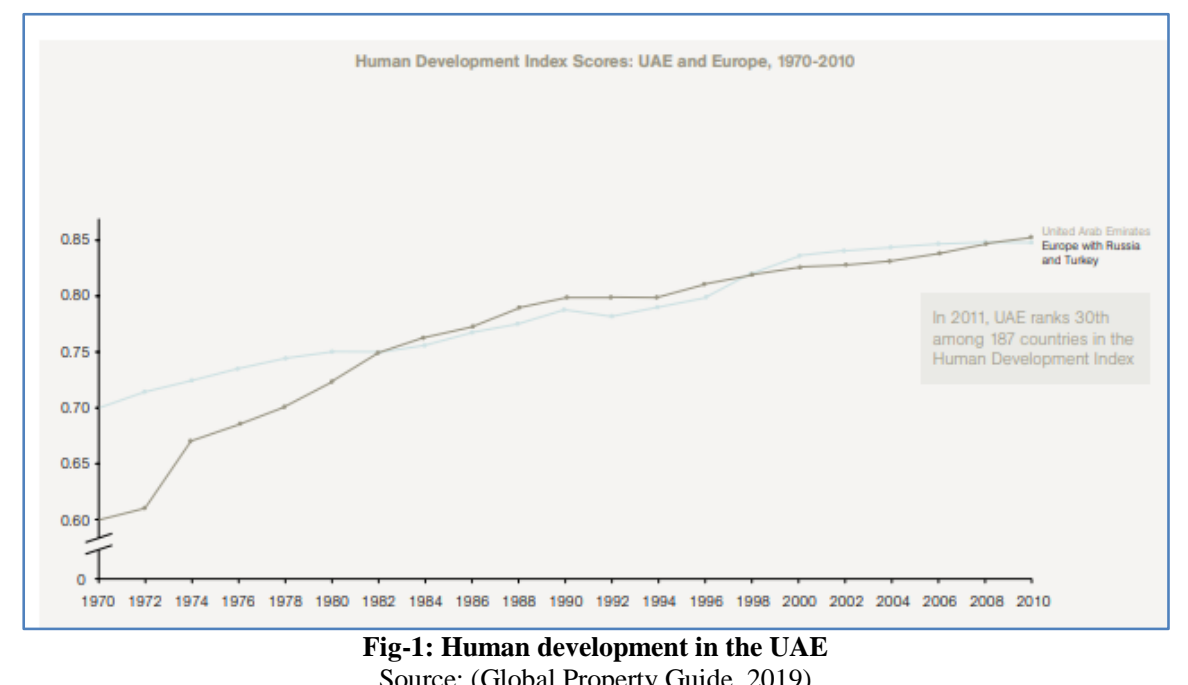

Source: (Global Property Guide, 2019) 


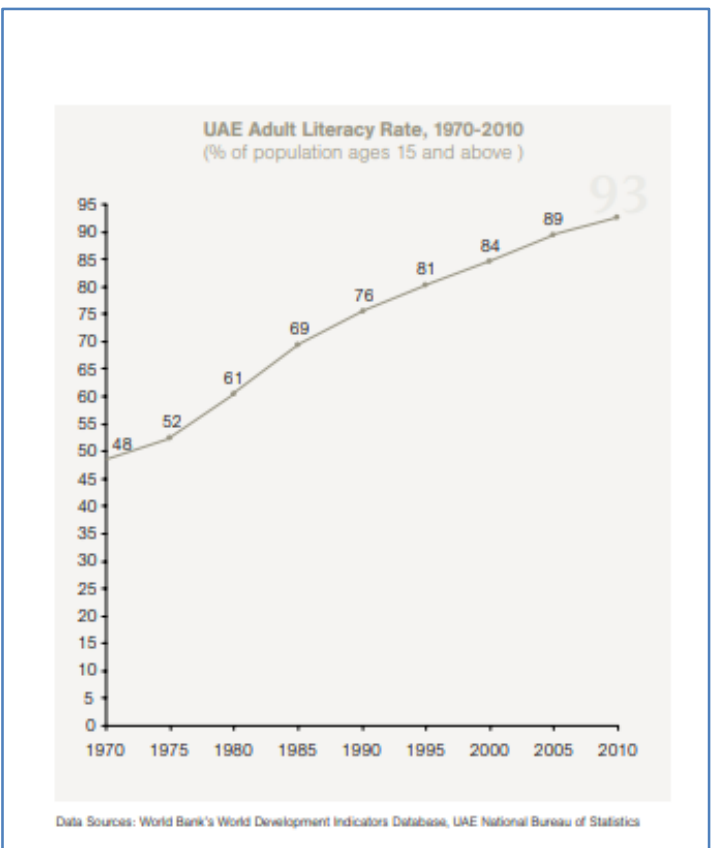

Fig-2: The literacy rate in the UAE Source: (Global Property Guide, 2019)

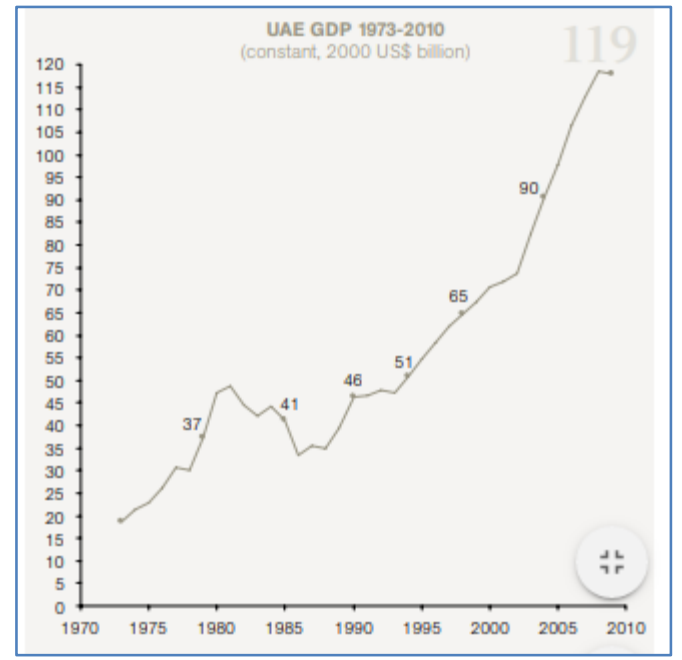

Fig-3: The GDP rate in the UAE

Source: (Global Property Guide, 2019)

From the above illustrated three figures, it is reflected that the UAE is positively moving towards the development. The human development sector, literacy rate and GDP are continuously on positive trend from 1970-2010. In the context of the real estate sector, the figure is shown below that reflects the positive trend of the nation in the real estate sector.

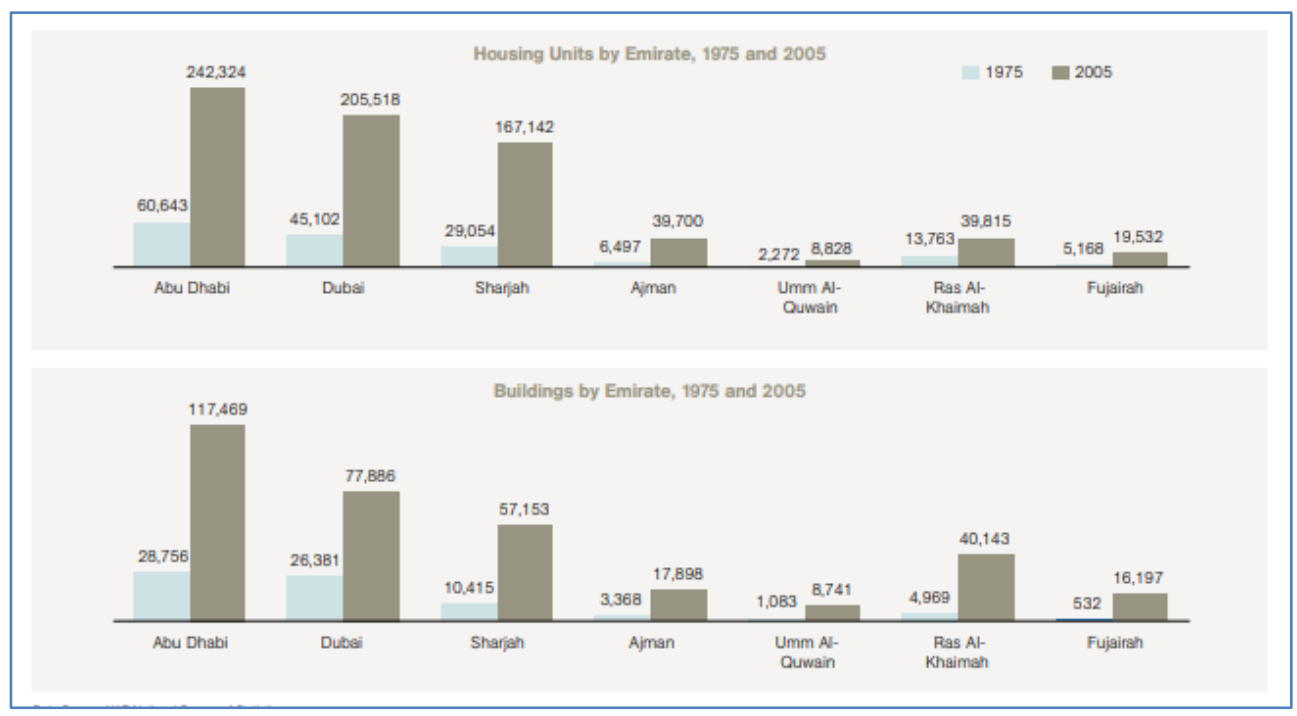

Fig-4: The real estate sector in the seven states of the UAE Source: (Global property guide, 2019)

The above multi-faceted consideration of the nation's significant transformation for the period of 40 years from 1970-2010 shows the accomplishments in fundamental areas of the country's economy such as human development, GDP, literacy rate and housing, buildings sector, however, a glimpse of previous statistics show [7] that the real estate market in the UAE is heading down since 2014 due to $9.5 \%$ fall in the Residential Property Price Index (RPPI). For the period 2002-2008, the property prices in the UAE, particularly in the Dubai increased up to four times due to the increased scope in the development sector such as Jumeirah Garden City, Dubai land, The Lagoons, but in
2008, due to the global financial crisis the foreign investors vanished, which decreased nearly half of the construction projects in the UAE i.e. 1.1 trillion Emirati Darham (US\$583 billion).

\section{Real Estate Market in the UAE from 2008 till 2019}

According to Hepsen \& Vatansever [11], before the global financial recession, UAE property market was flourishing in the global market, however, it drastically changed due to the significant decline observed in the foreign direct investment after 2008. This reduced the real estate sector by $1.6 \%$ in 2009 in UAE, amongst which Dubai is the notable economy 
where the foreigners either cancelled their projects or halted them for infinite time. Due to this loss of international funding, the gradual decline observed in the UAE overall property sector. Subsequent to the hopes raised in the global financial market in the year 2012 onwards, the gradual increase had been observed in the UAE real estate sector and since then the region is booming in the property sector and is likely to progress in the upcoming years due to the major project implementation of Dubai Expo 2020 and Dubai's City scape Global 2019, which attracted the attention of various foreigners to make investments in the UAE's regional economy, specifically in the Dubai region.

\section{Foreign Direct Investment in the UAE's Real Estate Sector}

Historically, foreign direct investment in the UAE has proved as a paramount contributor in the nation's economic development, particularly it is the leading factor in the region's GDP. Although, from 2008 the inward capital flow from the foreigners decreased from all time high i.e. $12.5 \%$ to $1.23 \%$ in 2010 with annual average rate of $2.3 \%$ from 2008-2013. This reduction in the foreign direct investment is linked with the poor financial and economic situations. The research exhibits that the Dubai's RPPI reduced by $11 \%$ and Abu Dhabi's RPPI reduced by $0.8 \%$ in 2015 due to the increase in the US Dollar prices, geopolitical stress in the Middle Eastern countries, reduction in the global oil prices and robustness of the central bank's Federal Mortgage capitalization [12].

The previous literature shows that from 20162018, the property prices in the UAE region, particularly in Dubai and Abu Dhabi is plummeted by $8.56 \%$ and $6.9 \%$ respectively. However, in 2018, offplan sales transactions increased by $30 \%$ in the UAE, but in 2019 from January till March, the ratio reduced to $7.8 \%$. The survey shows that the situation in the UAE is now changed in the context of the real estate property due to which the UAE's economy is expected to grow by $1.7 \%$ in 2019 after the sharp decline from the 2016 till 2018 and is anticipated to accelerate by the end of 2019 and the next year due to progression in the non-oil activities.

\section{The Increased Confidence in the Foreign Investors in the Real Estate Market in the UAE}

The research [4] exhibits that foreigners are now getting liberal in making investments in the UAE's real estate sector due to the following factors;

- Foreigners are now permitted to purchase freehold properties in the Dubai

- Due to the initiation of Abu Dhabi's regulations in 2014, foreigners are now allowed to purchase and own the property in the designated areas on freehold basis,

- In the global property context, the Gross rental offerings in Dubai is good, which offers higher returns even on the smaller apartments i.e. 90 sq. $\mathrm{m}$ equals to $5.91 \%$ and medium apartments i.e. 120 sq. $m$ offer yields equal to $5.19 \%$

- In 2018, the judicial authority initiated new regulations for the landlords to remove tenants easily. This increased the confidence level of the foreigners to increase their investment mechanism in the UAE region

- The UAE's economic growth is enhanced by $1.7 \%$ in 2018 as compared to the $0.8 \%$ in the previous year that reduced from $4.8 \%$ in the 2016 due to global financial market.

- UAE's oil market is increased by $1.94 \%$ in 2019 that was reduced to $1.5 \%$ from $3.2 \%$ in the previous years from 2016-2018 ( Global property guide, 2019)

- The reduction in the cost in the real estate sectors and education increased the confidence of the foreign investors to expect the economic growth in the non-oil sector in the upcoming years.

- Dubai expo 2020 is a proven catalyst for the UAE to increase its global presence in the corporate industry.

- The reduction in the rental property in the UAE makes the real estate market commended for the foreigners to enter the market for the long term investment.

- Flexible payment plans in the UAE property market that are provided on off-plan projects appeal the pool of investors to purchase the properties.

- Due to demand-supply gap, foreign developers are increasingly concerned about their investment opportunities in the UAE. Rent to own scheme is one notable example that has attracted the foreign investors to make prominent developments in the UAE such as Dubai sports city and Al-furjan development

- The implementation of new regulations such as 10year residency visa in the UAE allows eligible foreigners to feel permanence in the country and own a property in the region.

- The technological developments in the UAE enforced the real estate investors to increase their investment in the property sector. For instance, Real Estate Self-Transaction platform and the Tagyimee are notable examples of digitalization that has made easier for the investors to access their property regions from smart phone applications and evaluate the value of the property in the UAE. This connects the potential investors with the real estate property sellers, which reduces time and expenses included in the entire process.

- Dubai Cityscape Global 2019 acts as the major gateway for the foreign investors to make investment in the UAE real estate sector.

\section{CONCLUSION}

From the provision of the new regulations, developments and flexibilities in the real estate sector, 
UAE has strengthened its strategic global presence over the past few years. However, the literature shows that from 1970-2010, the country has encountered the booming trend in its overall economy, which attracted foreign investors to make investment in the economic development, yet, in 2008, the region started facing decline in its economic progression due to global financial crisis. From 2016 onwards, the region has again enacted the global recession due to reduction in the oil prices and strengthening dollar prices and introduced various new regulations in the real estate sector, which is now enforcing the country towards progression and development. The UAE's market is turning creative and maturing for the developers with its various offerings that stimulate the foreign investors and meet the consumer demand in the real estate market in the UAE.

\section{REFERENCES}

1. Global Property Guide. The UAE's house prices are now falling.2015; Retrieved from https://www.globalpropertyguide.com/Middle-

East/United-Arab-Emirates/Price-History-

Archive/the-uaes-house-prices-are-now-falling127334.

2. Hodgson E. The changing face of real estate in the GCC; 2019. Retrieved from https://gulfbusiness.com/changing-face-real-estategcc/.

3. Chinn M and Ito H. A New Measure of Financial Openness. Journal of Comparative Policy Analysis: Research and Practice.2008; 10(3), 309322.

4. Crompton B. Why the obsession with real estate in the UAE. 2018; Retrieved from https://www.thenational.ae/business/money/whythe-obsession-with-real-estate-in-the-uae-1.764198.

5. Al- Malkawi HN and Pillai R. The impact of financial crisis on UAE real estate and construction sector: analysis and implications. Humanomics. 2013; 29(2), 115-135.

6. Eid F and F Paua. "Foreign Direct Investment in the Arab World: The Changing Investment Landscape," Arab Competitiveness Report, World Economic Forum. 2003; 108-119

7. Aljifri $\mathrm{K}$ and Ahmad HI. Choosing Valuation Models in the UAE. Poesie Des Alltäglichen.2019; 191-203.

8. Modarress B, Ansari A and Lockwood D. Emiratization: from Policy to Implementation. International Journal of Human Resources Development and Management. 2013; 13(2), 188205. http://dx.doi.org/10.1504/IJHRDM.2013.055395

9. El-Mahmah A. "Constructing and Economic Composite Indicator for the UAE", UAE Central Bank, Research and Statistical Department; 2017.

10. Dreher A. Does globalization affect growth? Evidence from a new index of globalization. Applied Economics.2006; 38(10), 1091-1110.

11. Hepsen A and M Vatansever. "Forecasting Future Trends in Dubai Housing Market by using BoxJenkins Autoregressive Integrated Moving Average", International Journal of Housing Markets and Analysis.2011; 4(3), 210-223.

12. Rao I. Competing values in Asian business: evidence from India and Dubai. Journal of Asia Business Studies. 2019 Jan 7;13(1):97-107.

13. Global Property Guide. UAE's property prices continue to plummet; 2019; Retrieved from https://www.globalpropertyguide.com/MiddleEast/United-Arab-Emirates/Price-History. 